\title{
Meeting the Challenge of Learning for Sustainability Through Policy Networks
}

Adam Douglas Henry ${ }^{1}$

School of Government \& Public Policy, University of Arizona, United States of America

\section{Abstract}

Decision-making for sustainability is often confounded by the complex and ideologically divisive nature of policy issues surrounding coupled natural and human systems. However, some policy actors are more successful than others in learning to deal with these challenges. This study examines the extent to which variation in learning by organizations in the policy process is explained by an organization's position within a larger policy network. Mechanisms of interest include bridging and bonding social capital, which is hypothesized to promote learning, and network segregation, which is hypothesized to impede learning. Hypotheses are tested using statistical models applied to organizational network positions and perceptions of learning outcomes in three regional land use planning processes in California, USA. Results underscore the importance of bonding social capital and network expansiveness in promoting learning within complex issue domains. Certain forms of segregation are an important barrier to learning.

Keywords: network segregation, regional planning, social capital, social network analysis, sustainability science.

\section{Introduction}

A central challenge in the study of human ecology is to understand how to promote learning for sustainability within the policy process. Learning for sustainability refers to the process by which social actors develop a better knowledge of complex problems at the boundary of coupled natural and social systems and deploy this knowledge to better manage salient issues (Henry, 2009; Parson \& Clark, 1995; Social Learning Group, 2001).

Learning within the policy process is an important and distinctive form of learning. It is within the process of public policy-making that problems are defined, solutions formulated, and action is taken through the creation of new policies or programs. Thus the fate of many sustainability problems depends upon learning by "policy actors,"

1 Corresponding author: adhenry@arizona.edu. 
a term that refers to the many people and organizations that participate in the policy process and that represent a variety of interests within the public, private, and nonprofit sectors. ${ }^{2}$ These policy actors not only expend resources to pursue learning goals, but also hold power to enact meaningful change (Weible \& Sabatier, 2017).

This study asks: How does an actor's position within a policy network influence their capacity to learn for sustainability? "Policy networks" refers to the myriad ways in which policy actors interact with and relate to each other, including formalized collaborations as well as informal information sharing. Networks are endemic to the policy process (Victor et al., 2016; Weible \& Sabatier, 2017). Policy actors face a fundamental need to coordinate with others to expand their resources, knowledge, and power, all of which are critical learning resources. However, despite a broad understanding that networks are important to learning for sustainability (Bidwell et al., 2013; Henry \& Vollan, 2014; Masuda et al., 2018), there exists at least two important gaps between the current theoretical understanding of learning mechanisms, and empirical research on how these mechanisms operate in actual social systems.

First, it is widely believed that network actors who are linked to more diverse resources, knowledge systems, and worldviews are better equipped to deal with complex problems and develop innovative solutions to these problems (Bidwell et al., 2013). Theoretical agent-based modeling work supports this view (Hong $\&$ Page, 2004), however there is relatively little empirical evidence regarding the association between network segregation (an inverse measure of diversity) and learning (Henry \& Vollan, 2014). At the same time, the assumption that network segregation inhibits learning is implicit in many policy theories and underlies many organizational practices (Henry, 2016).

Second, the embeddedness of actors within larger systems is understood to influence learning, however there is a relative lack of empirical evidence on the precise nature of these connections. For instance, Armitage et al. (2018) study the influence of "enabling conditions" on learning, such as the types of activities policy actors engage in or the overall level of conflict in the system. Heikkila and Gerlak (2013) review many contextual factors that help explain learning, including process design and underlying social dynamics. Networks offer a useful measure of how actors are embedded in larger systems; certain network positions create access to social capital, while other positions may impede learning. While there is an emerging body of research on how networks create social capital and in turn enable learning (Stewart $\&$ Tyler, 2019), further work is needed to understand how and why network position matters for learning.

2 This research views policy actors as organizations (and thus organizations are the "learning actor"); however, the theory and hypotheses examined below are applicable to learning by individuals as well. 
This paper narrows the gap between theory and evidence through an examination of two theoretically-prominent mechanisms by which networks influence learning: through the creation of bridging and bonding social capital (Burt, 2000; Lin, 1999), and through the reduction of network segregation (Freeman, 1978b). These mechanisms are studied in the context of regional land use planning in three regions of California, United States of America (USA). Regional planning is a prototypical issue of sustainable development. Regional planning is fundamentally concerned with the problem of how to deal with rising populations and corresponding demand for infrastructure and services, while protecting Earth's local and global life-support systems. Actors involved in planning are continually engaged in various forms of learning, including belief updating through social interaction (Friedkin \& Johnsen, 2011; Marsden \& Friedkin, 1993), diffusion of innovations (Strang \& Soule, 1998; Valente, 1995), and the synthesis of information for problem-solving (Hong \& Page, 2004).

While there exist many pathways to learning, the fundamental goal of learning by policy actors is to craft solutions to manage, and perhaps even solve, policy problems. This research makes use of perceptual measures as a proxy for learningthat is, the extent to which policy actors believe that various forms of learning have taken place. While the empirical focus is on regional planning, the methods and general approach are also applicable to a wide variety of other policy domains that deal with complex human/environment interactions, placing this research firmly within human ecology and the field of sustainability science (Clark \& Dickson, 2003; Kates, 2011).

\section{Social capital and learning}

Social capital refers to the benefits that a person accrues from maintaining positive social relationships with other people. Just as cash in one's pocket is a form of capital that may be used when needed (e.g., when a person's home is flooded and they must pay for repairs), relationships with people is another form of capital that may be used in difficult times (e.g., when a person's home is flooded and they must ask others for a temporary place to live). ${ }^{3}$ Social capital is thought to be supported by a "virtuous triad" of trust, reciprocity, and social networks (Sabatier et al., 2005). Research on social capital has led to a rich tradition known as social capital theory, which has informed thinking about how network structures relate to fundamental social processes such as the evolution of cooperation and trust (Burt, 2000; Krackhardt, 1999; Lin, 1999; Simmel, 1950).

3 Of course, there are important differences between financial and social capital. Financial capital is gone once spent, however social capital is potentially replenished and perhaps strengthened over time as it is spent. Thank you to an anonymous reviewer for this insight. 
Given that relationships are a central feature of social capital, social network analysis provides a useful set of conceptual tools to both operationalize different forms of social capital and study its effects on learning. The following sections consider how the position of a particular policy actor (named Ego) reflects their available social capital, which in turn influences Ego's capacity for learning. Figure 1 depicts a hypothetical network with Ego as the focal actor; here, Ego has direct linkages with five other actors named $A, B, C$,

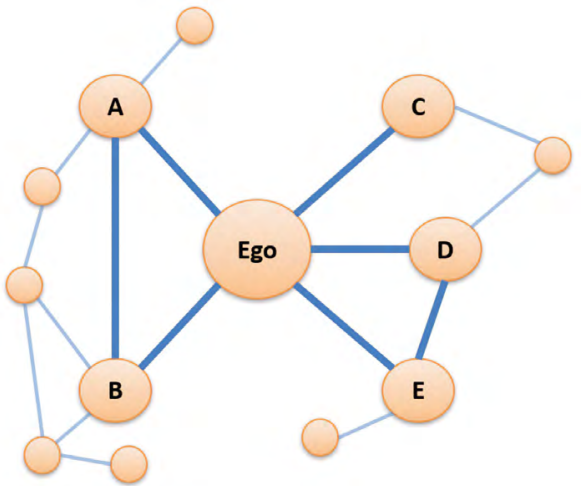

Figure 1. Hypothetical network with Ego as the focal learning agent.

Source: Author's representation. $D$, and $E$ - these actors are referred to as Ego's alters, and together they comprise Ego's network neighborhood.

Resources of various types flow within policy networks; information is exchanged, advice is given or received, and collaborators are sought out. These resources are raw ingredients for learning as organizations synthesize and apply information, knowledge, and expertise of various forms.

Occupying a central position in a network is useful for learning because it offers access to more of the social capital resources that the network has to offer. However, networks are also complex objects without a single natural center. Numerous concepts have been developed to assess whether an agent occupies a central network position (Freeman, 1978a; Wasserman \& Faust, 1994). One of the simplest and most widely used concepts is expansiveness, or degree centrality. A node's expansiveness is the number of linkages emanating from that node to other network actors. In Figure 1, for example, Ego has a degree centrality of five since Ego is linked to five alters.

Having high expansiveness can be beneficial for learning, since this centrality measure signals the overall amount of resources an agent has direct access to (that is, learning resources that exist within one degree of separation of Ego). Having many collaborators, for instance, can increase an organization's pool of expertise, which allows them to perform innovative analyses, or implement programs that benefit wider target audiences. In general, it is likely that actors occupying network positions with high expansiveness are more likely to learn due to having greater access to raw information resources that are necessary conditions for innovation and problem-solving:

$\mathrm{H}_{1}$ (expansiveness hypothesis): Network positions with high degree centrality tend to promote learning. 


\section{Bonding and bridging social capital}

While expansiveness may increase the potential for successful learning, access to information is a necessary but not sufficient condition for learning to take place (Heikkila \& Gerlak, 2013). The influence of network resources on learning depends on how relationships are structured among multiple agents, not just the overall number or density of relations (Bodin \& Crona, 2009). In other words, it is not just an organization's direct connections that matter for learning-it is how an organization is embedded within larger configurations and the network as a whole.

Social capital theory focuses on a tension between two distinct types of social capital, known as "bridging" and "bonding" forms of social capital. Bonding social capital is viewed as social capital that increases the cohesion of one's own community, while bridging social capital is viewed as social capital that creates access to outside communities. The distinction between bridging and bonding social capital is discussed in lucid reviews by Burt (2000) and Lin (1999), and is explored in numerous empirical applications (Berardo \& Scholz, 2010; Henry, Lubell, \& McCoy, 2011; Scholz et al., 2008).

Policy actors frequently rely on both forms of social capital in their day-to-day activities. For instance, bonding social capital is created when people form or strengthen ties with coworkers in an organization or research group; that is, those people who one must interact with on a regular basis. Bonding social capital may be viewed as a form of organizational capacity since groups with higher levels of bonding social capital are more likely to trust one another, cooperate effectively, and generally put the goals of the collective before their individual self-interest. Bridging social capital, on the other hand, is created when actors form or strengthen ties with others outside of their regular professional world. These types of relationships, famously labeled "weak ties" by Granovetter (1973), create a unique form of capital that comes from having access to different groups and the varied resources, such as information, skills, or perspectives, that exist within these groups.

Bridging and bonding forms of social capital are thought to be reflected in certain types of network structures. The conceptual starting point is the connected triadgroups of three actors where no single actor is isolated from the other two (Simmel, 1950). Bonding social capital is thought to be reflected in "closed triads," where all pairs of actors are connected (Berardo \& Scholz, 2010; Burt, 2000). For instance, the triad connecting actors A, B, and Ego in Figure 1 is a closed triad. Closed triads have the property that each pair of actors are both directly and indirectly tied such that "friends" are also "friends of friends." When a particular actor is part of many closed triads (relative to the total number of connected triads they are a part of), that actor is said to occupy a highly clustered network position. This reflects bonding social capital in the sense that clustered positions arise from actors making investments 
in relationships within their group. The creation of closed triads may be due to the spread of positive reputations, or the many opportunities that members of the same group have to form ties because of their close proximity or shared activities.

Bridging social capital, as noted above, is social capital derived from linkages that provide access to disparate communities. In contrast to bonding social capital and closed triads, bridging social capital is thought to be reflected in the existence of "open triads," or connected triads where one pair of actors is not connected (Berardo \& Scholz, 2010; Burt, 2000). In Figure 1, for instance, actors A, Ego, and C form an open triad. Ego stands at the apex of this particular open triad, and thus occupies a brokerage position between actors $\mathrm{A}$ and $\mathrm{C}$ - that is, in order for a resource, such as information, to flow from $\mathrm{A}$ to $\mathrm{C}$, the information must first pass through Ego.

\section{Bonding social capital, clustering, and learning}

Occupying clustered network positions high in bonding social capital may enhance Ego's potential for learning because these structures potentially strengthen relationships and promote greater levels of trust and reciprocity in the network (Henry \& Dietz, 2011; Henry, Lubell, \& McCoy, 2011; Scholz et al., 2008; Simmel, 1950). Suppose, for instance, that Figure 1 represents information-sharing relationships and Ego finds actor E to be a particularly trustworthy source of information. The fact that actors $\mathrm{D}$ and $\mathrm{E}$ share information sends a signal to Ego that D's information is also legitimate and trustworthy through the "transitivity" of trust - that is, Ego is more likely to trust a given actor if they have a positive relationship with a third actor that Ego already trusts.

This underscores the importance of trust in making network ties an effective vehicle for learning. The positive relation between clustering, bonding social capital, and learning is illustrated also by work emphasizing the importance of non-hierarchical information exchange and collaboration on belief change and innovation. For instance, the literature on the impact of discussion on political choices suggests that hierarchical information exchange structures (such as when one individual broadcasts a message to many passive agents) are less effective in promoting the adoption of new ideas than are information exchange structures that allow for discussion after a message has been broadcasted (Kerr \& Kaufman-Gilliland, 1994). In the policy process, hierarchical information exchange networks are primarily beneficial for those few central actors who can more efficiently influence the policy choices of a broad range of network actors. Evidence from the field suggests that innovation rarely occurs within such structures (Innes \& Booher, 1999). Rather, the primary benefit of information exchange relationships is that they provide a platform for agents to mutually synthesize knowledge and ideas. These considerations lead to the hypothesis that embeddedness in clustered structures has a positive influence on learning:

$\mathrm{H}_{2}$ (bonding social capital hypothesis): Highly clustered network positions tend to promote learning. 


\section{Bridging social capital, network brokerage, and learning}

A prominent idea in the study of social networks is that actors occupying boundaryspanning network positions are generally better off, because they can act as brokers between disparate and fragmented groups (Burt, 2004). Figure 1 illustrates a case where Ego occupies a high-brokerage position, because the groups of nodes to the left of Ego (including alters A and B) and to the right of Ego (including alters C, $\mathrm{D}$, and E) would be disconnected if Ego did not span the boundary between them. In terms of triadic structures, Ego's brokerage role is reflected in the fact that they stand at the apex of many open triads.

Occupying this brokerage role may enable learning because Ego is able to draw information from more diverse viewpoints (Burt, 2004). This view relies on the additional assumption that connected actors tend to share similar knowledge systems because many opportunities exist for learning within their clustered portion of the network. In Figure 1, for instance, Ego's linkage with both A and B is redundant-in this case B will most likely have the same information as A. Thus, Ego maximizes access to fresh information by seeking collaborations outside of clustered triads. Having a position with high brokerage is desirable because it allows Ego to sample many different paradigms and beliefs regarding the best way to tackle policy problems.

$\mathrm{H}_{3}$ (bridging social capital hypothesis): Network positions high in brokerage tend to promote learning.

$\mathrm{H}_{2}$ and $\mathrm{H}_{3}$ (Bonding and Bridging social capital hypotheses) are competing views because Ego's embeddedness in clustered structures, such as the interactions between Ego and alters $\mathrm{E}$ and $\mathrm{D}$, is at odds with Ego's position as a broker. In order to maintain this brokerage position, for example, no linkages may be formed between nodes A, B and C, D, E. Such a linkage would increase Ego's triadic embeddedness, but would also obviate Ego's role as a boundary-spanner.

$\mathrm{H}_{3}$ is limited in that it presumes that learning is largely an individual process that relies solely on having access to many different ideas and knowledge systems. Ultimately, whether $\mathrm{H}_{2}$ or $\mathrm{H}_{3}$ is more strongly supported should depend on Ego's intentions. Ego can facilitate information flow or block it; an actor with high brokerage can therefore learn more broadly or more selectively than actors with low brokerage.

\section{Network segregation, diversity, and learning}

A second mechanism through which networks influence learning is network segregation, meaning that relationships among policy participants tend to exist primarily among those actors with shared or similar characteristics (Freeman, 1978b). 
Network segregation is frequently observed in real-world networks, takes on a variety of forms, and is generally thought to impede learning. Three particularly important forms of network segregation in policy systems relevant to sustainability include (Schneider et al., 2003):

1. Belief-oriented segregation, meaning that networks tend to create more connectivity among organizations with shared systems of policy-relevant beliefs.

2. Functional domain segregation, meaning that networks tend to create more connectivity among organizations operating within similar policy issues such as natural resources management, energy, or transportation.

3. Governmental sector segregation, meaning that networks tend to create more connectivity among organizations operating within similar sectors or governmental jurisdictions such as the national, regional, or municipal level.

As noted above, policy scholarship puts heavy emphasis on the role of network segregation as a barrier to learning (and network "diversity" or "integration" as a positive driver of learning). At the same time, however, there is a paucity of research on the association between learning and network segregation, the contextual factors that might cause this association to vary, and the mechanisms that link these two concepts. It is therefore useful to develop additional hypotheses of how various forms of segregation matter for learning.

\section{Belief-oriented segregation and learning}

Many policy networks are structured through a process of belief homophily, meaning that network actors tend to form ties with others that share similar systems of beliefs (Sabatier \& Jenkins-Smith, 1993; Weible et al., 2011). Belief homophily is a powerful force in generating segregated networks (Henry, Pralat, \& Zhang, 2011) and is believed to be a result of fundamental cognitive biases that cause policy actors to systematically interpret disconfirming evidence in a way that confirms their prior beliefs (Dandekar et al., 2013; Innes, 1978; Lord et al., 1979; Munro \& Ditto, 1997; Munro et al., 2002). This process, known as biased assimilation, tends to erode trust among policy actors with divergent beliefs as they tend to interpret evidence in different ways (Leach \& Sabatier, 2005). The result is an organization of policy networks that are globally diverse, but homogenous within local neighborhoods. ${ }^{4}$

Despite the negative effect of biased assimilation on networking between ideologically dissimilar policy actors, it is still common for actors to seek information and advice from sources they do not necessarily agree with. There are several reasons why this may happen. First, more information is usually better than less information,

4 This perspective is a central component of the Advocacy Coalition Framework (ACF; Sabatier \& JenkinsSmith, 1993; Weible et al., 2011). The ACF is a prominent theoretical perspective on the policy process that focuses on the role of belief systems in driving political conflict in policy issues with high technical complexity and ideological polarization. 
especially from the point of view of boundedly rational actors who routinely operate with imperfect information. Second, there may not be enough information sources to give policy actors the option to seek information from ideologically similar sources. Third, it is usually advantageous to understand one's competitors, and going to them for information is a useful way to better understand their strategies and resources.

For these reasons it is hypothesized that belief-oriented segregation reduces the propensity to learn:

$\mathrm{H}_{4}$ (belief segregation hypothesis): Occupying a network position that is segregated in beliefs tends to inhibit learning.

\section{Functional domain segregation and learning}

Segregation across functional domain is problematic in the sense that it inhibits the synthesis of knowledge and decision-making authority on discrete problems that are closely coupled, such as issues of land use versus transportation (Cervero, 2002, 2003) or the sustainable provision of food, clean water, and renewable energy (Tilman et al., 2009). Network segregation works against the cross-disciplinary cooperation that is widely believed to be necessary to manage complex and interlinked policy problems. As a result, networks that segregate actors working in disparate functional domains are hypothesized to impede learning:

$\mathrm{H}_{5}$ (functional domain segregation hypothesis): Occupying a network position that is segregated in functional domains tends to inhibit learning.

\section{Governmental sector segregation and learning}

Effectively dealing with complex policy issues requires collaboration across sectors (such as between governmental and nongovernmental organizations) and vertical levels within the governmental sector (such as between local, state, and federal governmental organizations). Empirical research supports the proposition that this type of integration supports positive learning outcomes. For instance, research on governmental innovations in water sustainability across three countries suggests that innovations are more likely to be adopted when they have the support of policy actors operating within two or more levels of government (Daniell et al., 2014).

Governmental sector segregation will work against the cross-scale and cross-level interactions that are believed to be critical to the effective management of complex policy problems (Cash et al., 2006). Interaction across governmental sector produces resources - such as information-that are relevant to the needs and problems faced by policy actors (Mitchell et al., 2006). Scope of information is one determinant of relevance. Many policy systems focusing on issues at the local or regional scale use information produced primarily at the state or federal level, as is the case with 
Marine Protected Areas in California (Weible \& Sabatier, 2005). Local knowledge systems are sometimes ignored or marginalized within policy processes, making sustainable outcomes far more difficult to achieve (Cash et al., 2003).

These considerations lead to the hypothesis that network segregation across governmental sector inhibits learning:

$\mathrm{H}_{6}$ (vertical segregation hypothesis): Occupying a network position that is vertically segregated tends to inhibit learning.

\section{Methods}

The above hypotheses are tested using survey data from policy actors in regional land use planning processes in three metropolitan regions in California, USA, including Sacramento, San Diego, and Riverside County. While the issue of central concern is land use, processes also tend to include adjacent policy issues such as transportation planning and natural resources management. Transportation planning is particularly relevant as there exists formal regional governments in the USA that are tasked with the formation and implementation of transportation plans, which are required to be integrated with local land use plans. The three study regions in question correspond to transportation planning regions, where there also exists a substantial amount of coordination among local governments on land use concerns.

Archival sources were used to identify actors from a wide diversity of organizations, including organizations from the public, private, and non-profit sectors, as well as a diversity of governance processes such as those related to transportation, land use, and natural resources. The archival sources used, all publicly available, include state-maintained lists of planning professionals, local government websites, as well as records of comments made on environmental impact statements.

Potential respondents were recruited by email to participate in an online survey. ${ }^{5}$ Individuals who did not respond to this invitation (after three follow-up reminders) were asked to participate in a computer-assisted telephone interview (CATI) instead of the online survey. Overall, 514 survey responses were obtained from policy participants in the three regions, for an overall response rate of 34 percent. $^{6}$

Although the survey sampled individuals, organizations are treated as the unit of analysis. Individual survey respondents were asked questions in the context of their professional activities within their organization; these responses were then aggregated to the organizational level by averaging the responses of affiliated

\footnotetext{
5 A copy of the survey instrument is available from the author upon request.

6 This includes a total of 291 respondents from Sacramento (response rate 42\%), 116 respondents from Riverside (response rate 25\%), and 107 respondents from San Diego (response rate 30\%).
} 
respondents. Organizations in the final sample represent a diverse set of interests from across the public, private, and non-profit sectors. Organizations include local governments, state and federal agencies, interest groups, and business and industry groups, among others.

While respondents are drawn from three relatively distinct regional policy processes, the empirical analysis pools data from the three regions in order to examine average effects of network position on learning.

\section{Network measurement}

Network relationships were measured by asking survey respondents to nominate organizations they collaborate with (collaboration network), organizations that they go to for information or advice (information network), and organizations that they trust in the context of regional planning processes (trust network).

The structure of the regional collaboration, information, and trust networks are then estimated at the level of organizations and stakeholder groups based on connecting individual responses with the organizations they represent. Organizations A and B are assumed to be linked within the network if at least one respondent affiliated with Organization A or B nominated the other organization in a given network question. All ties are assumed to be equally influential in their effect on learning. Thus the networks estimated from the survey data are both undirected and unvalued.

Measured networks are depicted schematically in Figure 2. Policy networks within the three regions are relatively large (including many actors) and dense (with many relationships interconnecting these actors), thus it is difficult to see clear trends from looking at the graphics alone. However, there are a few noteworthy patterns. First, collaboration networks tend to be far more dense than either trust or information networks in the same region. This is expected in the case of information networks given that information is one type of collaboration. However, this is somewhat unexpected in the case of trust. In these systems, there are many instances of organizations that nominate each other as collaborators, but not necessarily as trusted collaborators.

Another interesting pattern is that the degree centrality of a node in the collaboration network (represented as the size of the node in Figure 2) does not necessarily translate into being a central actor in the trust or information networks. That is, some actors that are central information hubs are not central collaboration hubs. This shows that policy networks may have quite different structures within the same system depending on the relation of interest, and underscores the need to test the same set of hypotheses using different operationalizations of a policy network. 


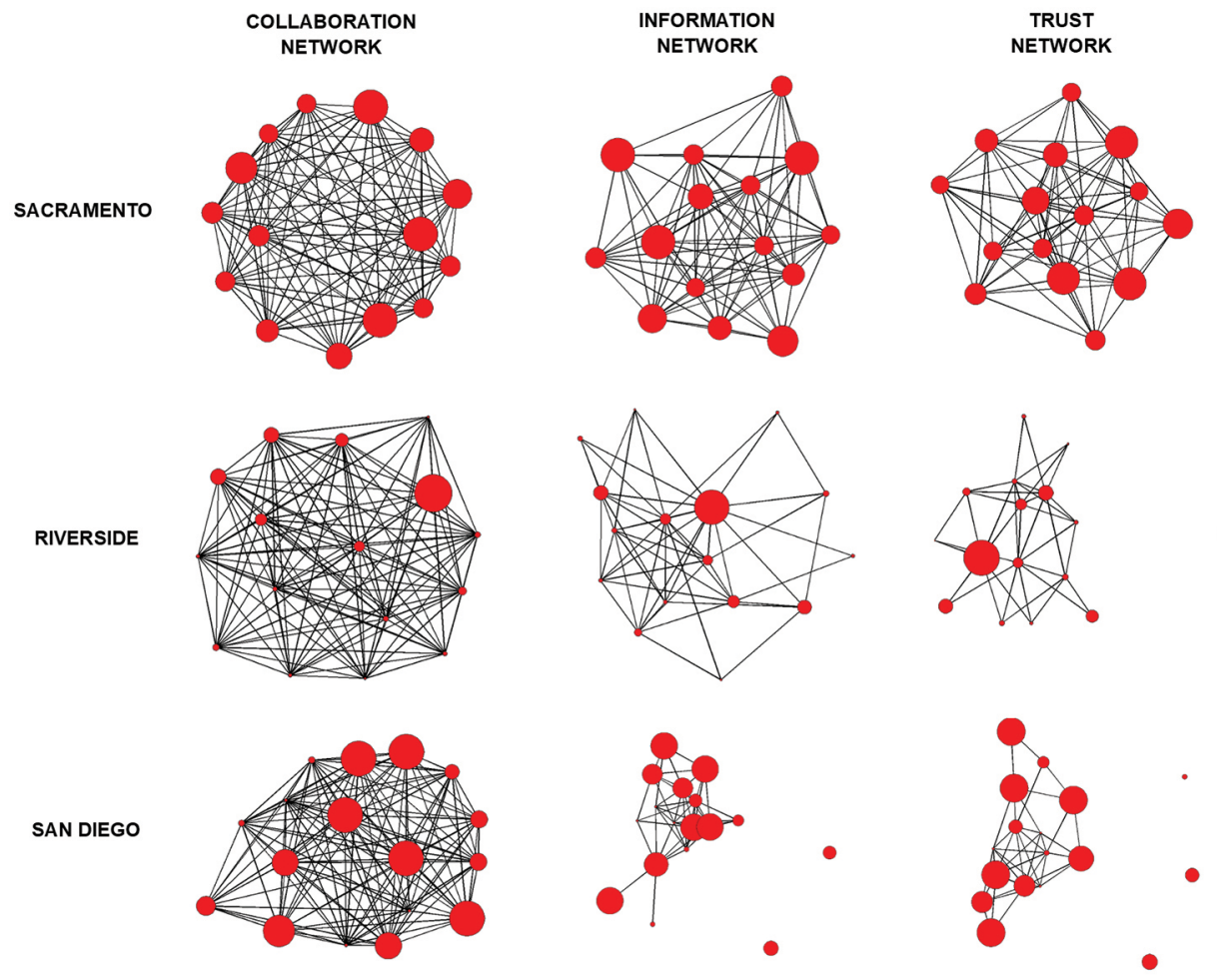

Figure 2. Measured policy networks in three regional processes.

Note: Network nodes represent organizations; links represent the specified relationship. Only the 15 most central actors in each network are shown. For comparability, node sizes are scaled according to the expansiveness of the organization in the collaboration network.

Source: Author's summary of survey results.

\section{Hypothesis testing approach}

Hypotheses of how local network positions influence learning are tested by fitting regression models using individual organizations in the policy network as the unit of analysis; in this case, perceptions of learning are taken as dependent variables, and characteristics of actors' position within the network are taken as independent variables. Variables measured for each organization include:

Learning (the dependent variable). This variable reflects overall perceptions of the probability of success of the regional planning process, including "the likelihood that current land use and transportation planning processes will improve regional problems in your area," and "the frequency with which regional land-use and transportation planning generates innovative policies in your area." A total of 12 similar items were scaled together to generate a measure of perceived learning $(\alpha=0.80)$. Perceptions of learning are not an ideal measure of learning as a theoretical variable, however perceptions of learning are likely to be at least correlated with 
actual decisions and innovations that would count as learning, and may even be a necessary condition for learning to take place. The use of a perceptual measure of learning also allows for a test of null results. That is, if a given factor influences perceptions of learning then that factor may or may not influence actual learning; on the other hand if a given factor does not even influence perceptions of learning then it is very unlikely to have any effect on learning as policy or behavioral change.

Belief-oriented segregation. Seven distinct measures of policy-relevant beliefs were measured in the survey, including three distinct beliefs regarding the perceived severity of regional planning problems, the appropriate role of the various stakeholders in the decision-making process, environmentalism, economic conservativism, and support for smart growth planning theory. The average belief distance between organizations is defined as the Euclidean distance between the average belief score in these seven dimensions between a given pair of organizations.

Functional domain segregation. Participation in policy-making venues-which is congruent to the theoretical notion of functional domains discussed aboveis measured for each respondent by asking the frequency with which they engage in various policy-relevant activities, including city planning, transportation planning, and natural resources planning, among other common venues of local governance. The degree of fragmentation in terms of cross-domain interactions is then measured as the Euclidean distance of the frequency of organizational pairs' participation in these various functional domains, or decision-making venues.

Governmental sector segregation. Segregation in terms of sector and vertical level of government is measured by the proportion of actors that a particular organization is connected to that are not in the same sector. The organization sector attribute takes on four possible values, including: regional or local (including regional Councils of Government or city/county governments), state, federal, and nongovernmental actors.

Collaborative institutions. A control variable is included that captures the degree to which an organization participates in regional collaborative institutions. Following a global trend in policy processes surrounding sustainability (Pretty, 2003), the regions studied here have all implemented a collaborative policy process (Lubell et al., 2010). These processes seek to engage a broad array of stakeholders in the policy process and promote a broad range of interactions thought to resolve barriers to learning (Sabatier et al., 2005). While this mechanism should theoretically operate through networks (that is, a collaborative process will enhance learning due to the changes it causes in one's network), the effect of collaborative participation controlling for networks is explicitly tested by including a variable capturing whether a majority of organizational representatives participate in the regional collaborative process. 


\section{Results}

Table 1 summarizes model results when the network positions of organizational actors are viewed as independent variables influencing on perceptions of learning. Reported model results are from ordinary least squares (OLS) regression with robust standard errors. ${ }^{7}$

Table 1. Perceptions of learning by individual network actors across three California regions.

\begin{tabular}{|c|c|c|c|c|c|c|}
\hline \multirow[b]{2}{*}{ Variable } & \multicolumn{2}{|c|}{ Collaboration networks } & \multicolumn{2}{|c|}{ Information networks } & \multicolumn{2}{|c|}{ Trust networks } \\
\hline & Model 1 & Model 2 & Model 1 & Model 2 & Model 1 & Model 2 \\
\hline \multicolumn{7}{|c|}{ Social capital effects } \\
\hline Degree centrality & $\begin{array}{l}0.010^{* * *} \\
(0.003)\end{array}$ & $\begin{array}{c}0.012^{* * *} \\
(0.003)\end{array}$ & $\begin{array}{l}0.015^{* *} \\
(0.005)\end{array}$ & $\begin{array}{l}0.015^{* *} \\
(0.004)\end{array}$ & $\begin{array}{c}0.017^{* * \star} \\
(0.004)\end{array}$ & $\begin{array}{c}0.020^{* * *} \\
(0.005)\end{array}$ \\
\hline $\begin{array}{l}\text { Clustering } \\
\text { coefficient }\end{array}$ & $\begin{array}{l}0.555 * \\
(0.277)\end{array}$ & - & $\begin{array}{l}0.569 \text { * } \\
(0.279)\end{array}$ & - & $\begin{array}{c}0.275 \\
(0.236)\end{array}$ & - \\
\hline $\begin{array}{l}\text { Betweenness } \\
\text { centrality }\end{array}$ & - & $\begin{array}{c}-0.003 \# \\
(0.002)\end{array}$ & - & $\begin{array}{c}-0.002 \# \\
(0.001)\end{array}$ & - & $\begin{array}{c}-0.003 \# \\
(0.002)\end{array}$ \\
\hline \multicolumn{7}{|c|}{ Network segregation effects } \\
\hline Avg. belief distance & $\begin{array}{l}-0.161^{* *} \\
(0.060)\end{array}$ & $\begin{array}{c}-0.155^{\text {** }} \\
(0.060)\end{array}$ & $\begin{array}{c}0.026 \\
(0.076)\end{array}$ & $\begin{array}{l}-0.066 \\
(0.077)\end{array}$ & $\begin{array}{l}-0.110 \\
(0.071)\end{array}$ & $\begin{array}{l}-0.085 \\
(0.076)\end{array}$ \\
\hline Avg. venue distance & $\begin{array}{l}0.216^{* \star *} \\
(0.049)\end{array}$ & $\begin{array}{c}0.198^{* * *} \\
(0.044)\end{array}$ & $\begin{array}{l}0.120 \# \\
(0.065)\end{array}$ & $\begin{array}{l}0.152 \text { * } \\
(0.059)\end{array}$ & $\begin{array}{l}0.097^{*} \\
(0.046)\end{array}$ & $\begin{array}{l}0.092 \text { * } \\
(0.046)\end{array}$ \\
\hline $\begin{array}{l}\text { Percent cross-level } \\
\text { ties }\end{array}$ & $\begin{array}{c}-0.963^{* * \star} \\
(0.227)\end{array}$ & $\begin{array}{c}-1.019^{* * *} \\
(0.199)\end{array}$ & $\begin{array}{c}-0.898^{* * *} \\
(0.275)\end{array}$ & $\begin{array}{c}-0.607^{*} \\
(0.240)\end{array}$ & $\begin{array}{l}0.107 \\
(0.274)\end{array}$ & $\begin{array}{l}-0.173 \\
(0.278)\end{array}$ \\
\hline \multicolumn{7}{|c|}{ Collaborative institutions } \\
\hline $\begin{array}{l}\text { Majority } \\
\text { participation }\end{array}$ & $\begin{array}{c}0.116 \\
(0.075)\end{array}$ & $\begin{array}{c}0.114 \\
(0.075)\end{array}$ & $\begin{array}{c}0.056 \\
(0.093)\end{array}$ & $\begin{array}{c}0.106 \\
(0.091)\end{array}$ & $\begin{array}{c}0.020 \\
(0.084)\end{array}$ & $\begin{array}{l}-0.013 \\
(0.085) \\
\end{array}$ \\
\hline Constant & 2.860 & 3.369 & 2.909 & 3.192 & 2.678 & 3.041 \\
\hline $\mathrm{R}^{2}$ & 0.201 & 0.196 & 0.145 & 0.128 & 0.117 & 0.095 \\
\hline$N$ (organizations) & 239 & 243 & 132 & 146 & 200 & 211 \\
\hline
\end{tabular}

Note: Stars indicate significance levels: ${ }^{\star}=p<0.05 ;{ }^{* \star}=p<0.01 ;{ }^{* \star}=p<0.001$. Hash mark (\#) indicates $p<0.1$. Models 1 and 2 are alternative model specifications for each network type, introduced due to the strong correlation between clustering coefficient and betweenness centrality.

Source: Author's summary of results.

$7 \quad$ All statistical analysis was performed in Stata, Release 12. 


\section{Social capital effects}

In terms of social capital effects on learning, the hypothesis that degree centrality has a positive influence on learning outcomes $\left(\mathrm{H}_{1}\right.$, expansiveness hypothesis) appears to be supported across all models. That is, organizations with more collaborators, more information, and more trust are consistently reporting higher levels of perceived learning in these policy systems.

The effects of clustering and brokerage are somewhat less consistent. Since clustering and brokerage (measures of bonding and bridging social capital, respectively) are closely correlated, the problem of multicollinearity is managed by using two different model specifications (labeled Models 1 and 2) for each network. Model 1 includes clustering coefficient, and tests the effect of bonding social capital $\left(\mathrm{H}_{2}\right)$. Model 2 includes betweenness centrality, and tests the effect of bridging social capital $\left(\mathrm{H}_{3}\right)$. Betweenness centrality is an oft-used empirical measure of brokerage, and represents the number of shortest "geodesic" paths between pairs of actors that flow through a given organization. Betweenness centrality is thus a measure of the extent to which an actor creates connectivity between disparate communities in a network.

$\mathrm{H}_{2}$ (bonding social capital) is supported in the context of collaboration and information networks. That is, occupying a position high on bonding social capitalsuch that one's alters also tend to be connected with each other-appears to increase learning. Higher betweenness centrality (brokerage) seems to lead to smaller levels of learning in all three network contexts. This is a weak relationship but appears to be consistent across different network types. Thus $\mathrm{H}_{3}$ (bridging social capital) is not supported, and in fact the effect moves opposite to the hypothesized direction.

\section{Network segregation effects}

It is important to note that all the segregation concepts are operationalized in terms of "distance" measures, meaning how different on average an Ego organization is from their alters. Segregated positions will have smaller distance measures, while larger distance measures suggest more integrated, less segregated, positions. Thus, the network segregation hypotheses $\mathrm{H}_{4}, \mathrm{H}_{5}$, and $\mathrm{H}_{6}$ are predicting positive coefficients - that is, higher distances (less segregation) should produce greater perceptions of learning.

Results for segregation are surprising. Belief-oriented segregation and vertical segregation appear to increase learning (greater diversity decreases learning, as seen in the negative coefficients). Moreover, this effect is strongly significant in certain cases.

In terms of belief-oriented segregation $\left(\mathrm{H}_{4}\right)$, it appears that segregation only matters within collaboration networks, yet here it matters in the opposite direction as expected. In other words, greater belief-oriented segregation in a collaboration 
network appears to promote learning rather than inhibit learning. Following the logic of biased assimilation and belief homophily discussed above, this effect may be due to the difficulty of maintaining productive relationships with others holding divergent belief systems. Learning may be easier when one does not have to wrestle with belief and value conflict that often characterizes sustainability policy issues. Thus, $\mathrm{H}_{4}$ (belief segregation) is clearly not supported.

Of the segregation hypotheses, only $\mathrm{H}_{5}$ (functional domain segregation) operates as expected. Across all networks, results show that having more diversity in one's network in terms of functional domain (measured by venue participation) leads to higher perceptions of learning.

Similar to the result for belief-oriented segregation, it appears that sector segregation (for instance, when local governments work primarily with other local governments) is actually good for learning perceptions. This is contrary to $\mathrm{H}_{6}$ (governmental sector segregation). This may be because working with actors at a similar level of government assures that resources shared (such as information) are salient to one another's needs-thus, it may be advantageous to work with others who are primarily interested in issues at the same scope as issues you work in.

Finally, and controlling for these factors, participation within local collaborative processes does not appear to have a direct effect on perceptions of learning. As noted above, this may be because the benefits of collaborative institutions derive primarily from their influence on the network structures, which in turn are the proximate determinants of learning in these policy systems.

\section{Discussion}

The results shown here illustrate that networks may have a counterintuitive and surprising effect on learning. Despite the widespread belief that bridging social capital, or "brokerage" positions enhance learning, this study finds an opposite effect. In the context of the regional planning processes studied here it appears that more clustered networks high in "bonding" social capital tend to promote greater learning. Of course this should not be expected to be universally true- the effect of bridging versus bonding social capital will certainly be dependent upon contextual factors such as the amount of risk organizations incur when deciding to coordinate with other actors in the region (Berardo \& Scholz, 2010; Dietz \& Henry, 2008; Scholz et al., 2008).

The analysis of network segregation shows that segregation likely matters, however the way in which it matters depends upon the network being studied as well as the attribute on which networks are segregated. It is encouraging that functional domain segregation operates as expected — that is, tends to impede learning. This is consistent 
with a prominent belief that organizations benefit from creating connections that create diversity in expertise and knowledge systems (Bidwell et al., 2013). This belief is manifest in the strategies of many organizations that invest in the development of collaborative, boundary-spanning institutions in order to better manage complex problems and promote innovation (Henry \& Vollan, 2014; Hong \& Page, 2004).

At the same time, these results should temper the belief that diversity always promotes learning. Belief-oriented segregation may promote learning when it takes ideological conflict out of the equation. Governmental sector segregation may promote learning outcomes when it promotes the exchange of information that is more relevant to one's local needs. The exact mechanisms require further research, however the general lesson is that network segregation is not always going to be bad for learning and related outcomes, such as problem-solving and policy innovation.

Another interpretation of the observed positive relationship between network segregation and learning is that policy actors are comfortable in segregated networks. Without the need to collaborate with other actors who are very different, the transaction costs of participation in the policy process are kept low. This may facilitate less conflictual and "easier" decision-making, which for some respondents may translate to a positive perception of learning. It is the more conflictual processesthat force actors to question known processes and conventional beliefs-that may be needed to provoke deep learning. ${ }^{8}$

As with all scientific research, this study has limitations. The most important limitation concerns the operationalization of learning as perceptions about the policy process and the capacity of one's organizations to achieve learning outcomes. This view of learning still provides useful insights about how networks influence learning, since perception and actual learning outcomes are likely to occur together.

At the same time, future research should use measures of learning that are direct and multidimensional. A "direct" measure will be a measure of actual change in the beliefs or behaviors of policy actors, for instance the adoption of new policies (Berger et al., 2020) or the transmission of practices from one organization to another (Valente, 1995). A "multidimensional" measure will be one that accounts for the many forms of learning that occur within social and policy systems, including belief updating versus behavioral change, or individual learning processes such as trial-and-error policy experimentation versus social learning processes such as the diffusion of innovations between policy actors (Henry, 2016). Future research should seek to test theoretically-grounded hypotheses of learning using a variety of learning measures, in the context of different policy processes, and at varying levels of analysis such as the individual level, organizational level, and system level. 


\section{Conclusion}

Developing better theories of learning is crucial to the design of institutions that help us to successfully manage complex and ideologically divisive problems of sustainable development. Given the central role that networks play in learning, theories should explicitly consider the mechanisms by which one's position in a network explains variation in the potential for learning, as well as actual learning outcomes.

This paper contributes to such theoretical development by clarifying specific mechanisms through which networks are hypothesized to influence learning outcomes. These mechanisms are derived from prominent theories of social capital and network segregation, which are often invoked in the discussion of networks. However, there are few empirical tests of the hypotheses that social capital and network segregation matter for learning in sustainability. This is in part due to the difficulty of measuring learning-while this study uses an imperfect measure of learning perceptions, such a measure still enables an initial test of core hypotheses and allows identification of potential null effects.

Empirical tests show that social capital, as measured by overall numbers of connections, has a strong and consistent positive effect on learning in the regional planning processes studied here. Bonding social capital, in the form of occupying clustered network positions, also tends to promote learning. Bridging social capital, in the form of occupying positions of high brokerage, does not appear to influence learning. The effect of network segregation on learning depends upon the attributes on which the network is segregated as well as the type of network tie. Belief-oriented segregation in collaboration networks tends to impede learning, while belieforiented segregation in information networks has no discernible effect. These results are contrary to the widespread belief — reflected in both theory and in practicethat creating more diverse, boundary-spanning networks will always improve the capacity of actors to learn.

This study fits into a larger research program seeking the development of a more comprehensive, inclusive, and synthetic theory of learning for sustainability (Henry, 2009). More research is needed on how network positions influence learning outcomes, accounting for a variety of different issue contexts as well as a variety of different forms of learning. Research on learning will also need to account for the dynamics of network evolution. A complete theory of networks and learning will not only explain how network structures influence outcomes, but also how networks self-organize in ways that may impede learning and how certain institutions might generate networks that enhance learning. Design principles for these institutions need to be grounded in solid, tested theory regarding the learning for sustainability. 


\section{References}

Armitage, D., Dzyundzyak, A., Baird, J., Bodin, Ö., Plummer, R., \& Schultz, L. (2018). An approach to assess learning conditions, effects and outcomes in environmental governance. Environmental Policy and Governance, 28(1), 3-14. doi.org/10.1002/ eet. 1781

Berardo, R., \& Scholz, J. T. (2010). Self-organizing policy networks: Risk, partner selection, and cooperation in estuaries. American Journal of Political Science, 54(3), 632-649. doi.org/10.1111/j.1540-5907.2010.00451.x

Berger, L., Henry, A. D., \& Pivo, G. (2020). Integrated water management recommendations in practice: Coexistence of old and new ways in Arizona. Water Policy, 22(4), 501-518. doi.org/10.2166/wp.2020.307

Bidwell, D., Dietz, T., \& Scavia, D. (2013). Fostering knowledge networks for climate adaptation. Nature Climate Change, 3, 610-611. doi.org/10.1038/nclimate1931

Bodin, Ö., \& Crona, B. I. (2009). The role of social networks in natural resource governance: What relational patterns make a difference? Global Environmental Change, 19(3), 366-374. doi.org/10.1016/j.gloenvcha.2009.05.002

Burt, R. S. (2000). The network structure of social capital. Research in Organizational Behavior, 22, 345-423. doi.org/10.1016/S0191-3085(00)22009-1

Burt, R. S. (2004). Structural holes and good ideas. American Journal of Sociology, 110(2), 349-399. doi.org/10.1086/421787

Cash, D. W., Adger, W. N., Berkes, F., Garden, P., Lebel, L., Olsson, P., Pritchard, L., \& Young, O. (2006). Scale and cross-scale dynamics: Governance and information in a multilevel world. Ecology and Society, 11(2), Article 8 [online]. doi.org/10.5751/es01759-110208

Cash, D. W., Clark, W. C., Alcock, F., Dickson, N. M., Eckley, N., Guston, D. H., Jäger, J., \& Mitchell, R. B. (2003). Knowledge systems for sustainable development. Proceedings of the National Academy of Sciences, 100(14), 8086-8091. doi.org/10.1073/ pnas. 1231332100

Cervero, R. (2002). Induced travel demand: Research design, empirical evidence, and normative policies. Journal of Planning Literature, 17(1), 3-20. doi.org/10.1177/088122 017001001

Cervero, R. (2003). Road expansion, urban growth, and induced travel: A path analysis. Journal of the American Planning Association, 69(2), 145-163. doi.org/10.1080/ 01944360308976303

Clark, W. C., \& Dickson, N. M. (2003). Sustainability science: The emerging research program. Proceedings of the National Academy of Sciences, 100(14), 8059-8061. doi.org/ $10.1073 /$ pnas. 1231333100 
Dandekar, P., Goel, A., \& Lee, D. T. (2013). Biased assimilation, homophily, and the dynamics of polarization. Proceedings of the National Academy of Sciences, 110(15), 5791-5796. doi.org/10.1073/pnas.1217220110

Daniell, K. A., Coombes, P. J., \& White, I. (2014). Politics of innovation in multi-level water governance systems. Journal of Hydrology, 519(Part C), 2415-2435. doi.org/10.1016/ j.jhydrol.2014.08.058

Dietz, T., \& Henry, A. D. (2008). Context and the commons. Proceedings of the National Academy of Sciences, 105(36), 13189-13190. doi.org/10.1073/pnas.0806876105

Freeman, L. C. (1978a). Centrality in social networks: Conceptual clarification. Social Networks, 1(3), 215-239. doi.org/10.1016/0378-8733(78)90021-7

Freeman, L. C. (1978b). Segregation in social networks. Sociological Methods \& Research, 6(4), 411-429. doi.org/10.1177/004912417800600401

Friedkin, N. E., \& Johnsen, E. C. (2011). Social influence network theory: A sociological examination of small group dynamics. Cambridge University Press. doi.org/10.1017/ CBO9780511976735

Granovetter, M. S. (1973). The strength of weak ties. The American Journal of Sociology, 78(6), 1360-1380. doi.org/10.1086/225469

Heikkila, T., \& Gerlak, A. K. (2013). Building a conceptual approach to collective learning: Lessons for public policy scholars. Policy Studies Journal, 41(3), 484-512. doi.org/ $10.1111 /$ psj.12026

Henry, A. D. (2009). The challenge of learning for sustainability: A prolegomenon to theory. Human Ecology Review, 16(2), 131-140. www.jstor.org/stable/24707537

Henry, A. D. (2016). Network segregation and policy learning. In J. N. Victor, A. H. Montgomery, \& M. Lubell, (Eds.), The Oxford handbook of political networks (pp. 559588). Oxford University Press. doi.org/10.1093/oxfordhb/9780190228217.013.23

Henry, A. D., \& Dietz, T. (2011). Information, networks, and the complexity of trust in commons governance. International Journal of the Commons, 5(2), 188-212. doi.org/ 10.18352/ijc.312

Henry, A. D., Lubell, M., \& McCoy, M. (2011). Belief systems and social capital as drivers of policy network structure: The case of California regional planning. Journal of Public Administration Research and Theory, 21(3), 419-444. doi.org/10.1093/jopart/muq042

Henry, A. D., Pralat, P., \& Zhang, C.-Q. (2011). Emergence of segregation in evolving social networks. Proceedings of the National Academy of Sciences, 108(21), 8605-8610. doi.org/10.1073/pnas.1014486108

Henry, A. D., \& Vollan, B. (2014). Networks and the challenge of sustainable development. Annual Review of Environment and Resources, 39, 583-610. doi.org/10.1146/annurevenviron-101813-013246 
Hong, L., \& Page, S. E. (2004). Groups of diverse problem solvers can outperform groups of high-ability problem solvers. Proceedings of the National Academy of Sciences, 101(46), 16385-16389. doi.org/10.1073/pnas.0403723101

Innes, J. E., \& Booher, D. E. (1999). Consensus building as role playing and bricolage: Toward a theory of collaborative planning. Journal of the American Planning Association, 65(1), 9-26. doi.org/10.1080/01944369908976031

Innes, J. M. (1978). Selective exposure as a function of dogmatism and incentive. The Journal of Social Psychology, 106(2), 261-265. doi.org/10.1080/00224545.1978.9924177

Kates, R. W. (2011). What kind of a science is sustainability science? Proceedings of the National Academy of Sciences, 108(49), 19449-19450. doi.org/10.1073/pnas.1116097108

Kerr, N. L., \& Kaufman-Gilliland, C. M. (1994). Communication, commitment, and cooperation in social dilemma. Journal of Personality and Social Psychology, 66(3), 513-529. doi.org/10.1037/0022-3514.66.3.513

Krackhardt, D. (1999). The ties that torture: Simmelian tie analysis in organizations. Research in the Sociology of Organizations, 16, 183-210.

Leach, W. D., \& Sabatier, P. A. (2005). To trust an adversary: Integrating rational and psychological models of collaborative policymaking. American Political Science Review, 99(04), 491-503. doi.org/10.1017/S000305540505183X

Lin, N. (1999). Building a network theory of social capital. Connections, 22(1), 28-51.

Lord, C. G., Ross, L., \& Lepper, M. R. (1979). Biased assimilation and attitude polarization: The effects of prior theories on subsequently considered evidence. Journal of Personality and Social Psychology, 37(11), 2098-2109. doi.org/10.1037/0022-3514.37.11.2098

Lubell, M., Henry, A. D., \& McCoy, M. (2010). Collaborative institutions in an ecology of games. American Journal of Political Science, 54(2), 287-300. doi.org/10.1111/j.15405907.2010.00431.x

Marsden, P. V., \& Friedkin, N. E. (1993). Network studies of social influence. Sociological Methods \& Research, 22(1), 127-151. doi.org/10.1177/0049124193022001006

Masuda, Y. J., Liu, Y., Reddy, S. M. W., Frank, K. A., Burford, K., Fisher, J. R. B., \& Montambault, J. (2018). Innovation diffusion within large environmental NGOs through informal network agents. Nature Sustainability, 1, 190-197. doi.org/10.1038/ s41893-018-0045-9

Mitchell, R. B., Clark, W. C., Cash, D. W., \& Dickson, N. M. (Eds.). (2006). Global environmental assessments: Information and influence. The MIT Press. doi.org/10.7551/ mitpress/3292.001.0001

Munro, G. D., \& Ditto, P. H. (1997). Biased assimilation, attitude polarization, and affect in reactions to stereotype-relevant scientific information. Personality and Social Psychology Bulletin, 23(6), 636-653. doi.org/10.1177/0146167297236007 
Munro, G. D., Ditto, P. H., Lockhart, L. K., Fagerlin, A., Gready, M., \& Peterson, E. (2002). Biased assimilation of sociopolitical arguments: Evaluating the 1996 U.S. presidential debate. Basic and Applied Social Psychology, 24(1), 15-26. doi.org/10.1207/ s15324834basp2401_2

Parson, E. A., \& Clark, W. C. (1995). Sustainable development as social learning: Theoretical perspectives and practical challenges for the design of a research program. In L. H. Gunderson, C. S. Holling, \& S. S. Light (Eds.), Barriers and Bridges to the Renewal of Ecosystems and Institutions (pp. 428-460). Columbia University Press.

Pretty, J. (2003). Social capital and the collective management of resources. Science, 302(5652), 1912-1914. doi.org/10.1126/science. 1090847

Sabatier, P. A., Focht, W., Lubell, M., Trachtenberg, Z., Vedlitz, A., \& Matlock, M. (Eds.). (2005). Swimming upstream: Collaborative approaches to watershed management. MIT Press. doi.org/10.7551/mitpress/6577.001.0001

Sabatier, P. A., \& Jenkins-Smith, H. C. (Eds.). (1993). Policy change and learning: An advocacy coalition approach. Westview Press.

Schneider, M., Scholz, J., Lubell, M., Mindruta, D., \& Edwardsen, M. (2003). Building consensual institutions: Networks and the national estuary program. American Journal of Political Science, 47(1), 143-158. doi.org/10.1111/1540-5907.00010

Scholz, J. T., Berardo, R., \& Kile, B. (2008). Do networks solve collective action problems? Credibility, search, and collaboration. The Journal of Politics, 70(02), 393-406. doi.org/ 10.1017/S0022381608080389

Simmel, G. (1950). Quantitative aspects of the group. In The sociology of Georg Simmel (K. H. Wolff, Trans., Ed.) (pp. 85-177). Free Press.

Social Learning Group (Ed.). (2001). Learning to manage global environmental risks (Vols. 1 $\& 2)$. MIT Press.

Stewart, J., \& Tyler, M. E. (2019). Bridging organizations and strategic bridging functions in environmental governance and management. International Journal of Water Resources Development, 35(1), 71-94. doi.org/10.1080/07900627.2017.1389697

Strang, D., \& Soule, S. A. (1998). Diffusion in organizations and social movements: From hybrid corn to poison pills. Annual Review of Sociology, 24, 265-290. doi.org/10.1146/ annurev.soc.24.1.265

Tilman, D., Socolow, R., Foley, J. A., Hill, J., Larson, E., Lynd, L., ... Williams, R. (2009). Beneficial biofuels - the food, energy, and environment trilemma. Science, 325(5938), 270-271. doi.org/10.1126/science. 1177970

Valente, T. W. (1995). Network models of the diffusion of innovations. Hampton Press.

Victor, J. N., Montgomery, A. H., \& Lubell, M. (2016). The Oxford handbook of political networks. Oxford University Press. doi.org/10.1093/oxfordhb/9780190228217.001.0001 
Wasserman, S., \& Faust, K. (1994). Social network analysis: Methods and applications. Cambridge University Press. doi.org/10.1017/CBO9780511815478

Weible, C. M., \& Sabatier, P. A. (2005). Comparing policy networks: Marine protected areas in California. Policy Studies Journal, 33(2), 181-201. doi.org/10.1111/j.1541-0072. 2005.00101.x

Weible, C. M., \& Sabatier, P. A. (Eds.). (2017). Theories of the policy process (4th ed.). Westview Press.

Weible, C. M., Sabatier, P. A., Jenkins-Smith, H. C., Nohrstedt, D., Henry, A. D., \& deLeon, P. (2011). A quarter century of the advocacy coalition framework: An introduction to the special issue. Policy Studies Journal, 39(3), 349-360. doi.org/10.1111/j.15410072.2011.00412.x 
This text is taken from Human Ecology Review, Volume 26, Number 2, 2020, published by ANU Press, The Australian National University, Canberra, Australia. doi.org/10.22459/HER.26.02.2020.08 